\title{
O AMBIENTE VIRTUAL DE APRENDIZAGEM COMO LÓCUS DA FORMAÇÃO DE FACILITADORES JUDICIAIS EM JUSTIÇA RESTAURATIVA NO PODER JUDICIÁRIO DO RIO GRANDE DO SUL: RELATO DE UMA EXPERIÊNCIA INOVADORA.
}

\author{
PORTO ALEGRE/RS JUNHO/2018
}

\author{
Mary da Rocha Biancamano - PJRS - mary@tjrs.jus.br \\ Ana Paula Pereira Flores - PJRS - anaflores@tjrs.jus.br
}

Tipo: Relato de Experiência Inovadora (EI)

Categoria: Métodos e Tecnologias

Setor Educacional: EDUCAÇÃO CORPORATIVA

\begin{abstract}
RESUMO
O artigo registra a implementação da educação a distância como uma metodologia de ensinoaprendizagem, em acelerada expansão no Brasil, na formação de Facilitadores Judiciais dentro do desenvolvimento do Programa de Justiça Restaurativa para o Século 21 como uma política judiciária. A Justiça Restaurativa (JR) se encontra em momento de importante fortalecimento e difusão no Poder Judiciário do Estado do Rio Grande do Sul, no Brasil e no cenário internacional. Nesse contexto, a educação a distância, aplicada em ambiente virtual colaborativo e cooperativo, apresenta-se como um significativo instrumento de formação de pessoas para a viabilização do emprego de métodos autocompositivos em uma sociedade de alta demanda por meios de solução de conflitos e diminuição da violência, radicada em vasta área territorial. Sabe-se que a formação de qualidade de Facilitadores Judiciais é elemento fundamental no fortalecimento das políticas sociais em todas as esferas de governo, em que pese as ações da Justiça Restaurativa ainda demonstrarem a necessidade de maiores estudos em seus resultados. A metodologia EAD empregada na formação de Facilitadores Judiciais do Poder Judiciário do RS está alinhada aos princípios restaurativos de compartilhamento de responsabilidades, empoderamento, de participação, bem como se fundamenta na construção do conhecimento de forma dialogada e consensual; na responsabilidade por seu ser e fazer; na autonomia em ser sujeito de seu processo de aprendizagem; diálogo, em crescente interação dialógica com o outro. Como resultado principal desta formação no âmbito Poder Judiciário do RS, envolvendo a educação a distância como metodologia de ensino-aprendizagem, está, sem dúvida, a constatação de que a formação de Facilitadores Judiciais pode ser efetivamente realizada, com a qualidade necessária, por meio da utilização de atividades presenciais e vivencias e atividades teórico-práticas na modalidade a distância.
\end{abstract}

Palavras-chave: Educação a Distância. Facilitador Judicial. Justiça Restaurativa. Poder Judiciário do Rio Grande do Sul. 


\section{O CONTEXTO DE ONDE FALAMOS: Ambiente virtual de aprendizagem - AVA}

Um ambiente virtual de aprendizagem consiste em uma estrutura virtual, ou um software, que agrega diferentes recursos. Esses recursos, por sua vez, possibilitam ao aluno, a distância, e com apoio da internet, ler textos, assistir a vídeos, realizar exercícios e participar de reuniões virtuais síncronas, debater com colegas e professores de modo assíncrono, dentre outras possibilidades, que se tornam mais interessantes se pautadas por uma orientação pedagógica construtivista de busca pelo conhecimento. São exemplos de ambientes virtuais, dentre outros: Moodle, Teleduc, WebCT e NAVi/PJRS.

Nessa perspectiva, ao considerar a implementação de um programa de educação a distância, sua efetividade e eficácia, deve-se levar em conta a realidade do Poder Judiciário do RS: grandes distâncias geográficas, necessidade de formação e aperfeiçoamento dos profissionais das áreas meio e fim da organização, escassez de recursos financeiros e humanos, reflexo de problemas sociais, políticos e econômicos do País de solução de longo prazo. A opção pelo portal educacional Plataforma $\mathrm{NAVI/PJRS}$, recurso pedagógico fundamental nessa construção, centra-se nas características de apoio às atividades de ensino-aprendizagem, com estímulos a habilidades e atitudes de cada aluno, de colaboração e cooperação na construção e gestão do conhecimento.

Nesse sentido, o ambiente apresenta estrutura integrada para possibilitar oferecimento de diversos cursos e turmas ao mesmo tempo, de forma recursiva e integrada; enfoque na descentralização, em que os docentes podem prover, acessar e gerenciar autonomamente suas informações e funcionalidades; enfoque sistêmico, para acessar recursos e funcionalidades e informações via estrutura mais flexível, em rede e menos rígida e hierárquica; enfoque para uso de banco de dados e linguagem que garanta desenvolvimento e manutenção rápida de soluções. Assim, considerando os desafios e possibilidades apresentados como aspectos positivos da educação a distância na formação de pessoas, o Poder Judiciário do RS realiza cursos de aperfeiçoamento para magistrados, servidores e colaboradores, por meio do ambiente virtual de aprendizagem - Plataforma NAVI/PJRS.

\section{A Justiça Restaurativa, os Círculos de Construção de Paz e a Formação do Facilitador Judicial}

No Rio Grande do Sul, a área da Justiça Restaurativa foi objeto de estudos por grupo de magistrados, servidores e colaboradores, no ano de 1999, identificando-se uma primeira 
prática em 2002, em sede de execução de medida socioeducativa, no Juizado da Infância e Juventude de Porto Alegre (RS). A Escola Superior da Magistratura (ESM), no ano de 2005, se torna responsável pela gestão e execução do "Projeto Justiça para o Século 21", com atuação em unidades jurisdicionais do Poder Judiciário do Estado do Rio Grande do Sul e outras instituições parcerias em ações conjuntas.

No ano de 2014, o Poder Judiciário do RS implantou a Justiça Restaurativa como uma política judiciária, aprovando a utilização de práticas restaurativas no ambiente judicial por meio do Programa Justiça Restaurativa para o Século 21 (Programa JR21). Nesse ponto, o desafio se tornou a formação de qualidade para pessoas que pudessem atuar como Facilitadores Judiciais na área da Justiça Restaurativa e Construção de Paz do Poder Judiciário do Rio Grande do Sul que atendessem às demandas de atuação em situação de conflito com alta qualificação.

Esclareça-se que a Justiça Restaurativa pode ser operacionalizada por diferentes metodologias de atendimento, tais como: círculos de construção de paz, mediação vítima-ofensor, conferências familiares, círculos de sentenciamento, conferência restaurativa. Neste caso, a metodologia adotada pelo Programa JR21 foram os Círculos de Construção de Paz. A formação e o aperfeiçoamento de Facilitadores que atuam nos Círculos de Construção de Paz da Justiça Restaurativa requer a construção de conhecimento e o desenvolvimento de habilidades e atitudes para atuação nas situações requeridas de autocomposição de conflitos na esfera judicial. No âmbito do Poder Judiciário do RS, os eventos formativos iniciaram em maio de 2015 , envolvendo 12 unidades judiciárias distribuídas no Estado do RS, sendo 04 delas da Comarca da Capital e 08 de Comarcas do Interior, quais sejam: Caxias do Sul Novo Hamburgo, Pelotas, Passo Fundo, Lajeado, Santa Maria, Sapiranga e Guaíba.

Nessa edição de 2015, a formação trouxe a expectativa de certificação de 300 Facilitadores Judiciais, dentre magistrados, servidores e colaboradores. Relevante destacar que, a partir da edição da formação de 2016, o Programa JR21 passou a contar com a coordenação pedagógica do Centro de Formação e Desenvolvimento de Pessoas do Poder Judiciário (CJuD/PJRS), escola judicial do Tribunal de Justiça do Estado do Rio Grande do Sul, em consonância com as recomendações do CNJ[4], na área da formação e gestão de pessoas no âmbito do Poder Judiciário brasileiro.

\section{OBJETIVO:}

O objetivo deste artigo é apresentar os resultados encontrados por meio da metodologia EAD, dentro do Projeto Pedagógico do Centro de Formação e Desenvolvimento de 
Pessoas do PJRS, na formação específica de Facilitadores Judiciais de Círculos de Construção de Paz, ao priorizar o desenvolvimento de competências dos alunos por meio de atividades integrativas, interacionais e cognitivas em ambiente virtual colaborativo e cooperativo - Plataforma NAVI/PJRS.

\section{REFERENCIAL TEÓRICO: A Metodologia EAD: olho no olho através da tela}

A visão de que as novas tecnologias de comunicação provocaram o aparecimento de formas criativas de interação entre as pessoas, passando cada equipamento com acesso a Internet a ser uma grande janela para o mundo. O conhecimento pode ser construído e atualizado em tempo real, atingindo a todos os participantes de igual forma, em casa ou no trabalho. Muito se tem debatido sobre temas que levantam as vantagens e desvantagens do ensino presencial e do ensino a distância. Alguns com a crítica incisiva de que nada supera o "olho no olho" em um processo de aprendizagem, de que "estar em presença" faria grande diferença nos resultados do processo de construção do conhecimento. Entretanto, acredita-se que, por uma série de experiências e pesquisas realizadas nas mais diferentes universidades do mundo, em escolas e academias, em corporações, em organizações públicas e privadas, há uma mudança de paradigma inquestionável: o meio digital é o território de hoje, não mais do amanhã, e as tecnologias de comunicação provocaram o aparecimento de novas formas de interação entre os indivíduos, em que cada computador é uma janela, integrante de um sistema online.

Dessa forma, o Centro de Formação e Desenvolvimento de Pessoas do PJRS - CJud tem realizado eventos formativos nas modalidades a distância e mistos - ou híbridos. Nesse sentido, fomentam-se a reflexão sobre conceitos preexistentes e sua comparação com novas propostas; a socialização de experiências individuais, nos ambientes de interação - fóruns assíncronos e síncronos; a sistematização das contribuições individuais na forma de estudos de caso e relatos de experiências vividas, em que professores, tutores e alunos dispõem de espaço para externalização das contribuições e análises; a internalização dos conhecimentos pela objetivação possibilitada pela simultaneidade entre atividades e prática profissional.

Ao final, cada um e o grupo expressam-se e escutam, e novamente se expressam, construindo novos enunciados. Com essa visão norteadora do processo de ensinoaprendizagem em ambiente virtual, de relação custo-benefício, de conhecimento construído e atualizado em tempo real, atingindo a todos os participantes de igual forma, em casa ou no trabalho, uma vez que locais podem ser integrados e a aprendizagem coletiva realizada mediante funcionalidades interativas, foram implementados cursos de 
formação de Facilitadores Judiciais, na modalidade mista, ou híbrida. Importante ressaltar aqui que existem dois pontos norteadores do processo de ensinoaprendizagem, para que o aluno virtual atinja um bom desempenho em um evento formativo: interação e compartilhamento.

Em um ambiente virtual de aprendizagem, é importante considerar que todos se encontram separados geograficamente e - muitas vezes - em tempos diferentes. E nesse território virtual o aluno pode-se tornar autônomo nas suas escolhas de leitura, produção e reflexão. No sentido de fomentar e intensificar as ações na esfera da interação, por meio do diálogo entre pessoas que apresentam afinidade de interesses, identifica-se o potencial de uma comunidade virtual que tende a reforçar a coesão em torno de uma visão comum, fortalecer a identidade de seus integrantes e sua identificação com o grupo, ensejar a disseminação e a geração de conhecimentos e reforçar a cooperação na busca da satisfação de necessidades e objetivos comuns.

As tecnologias disponíveis e que passam a ser utilizadas pela EAD permitem realizar o antigo sonho da ubiqüidade, viabilizando, em tempo real, a máxima descentralização da informação, matéria-prima do trabalho intelectualizado. Tapscott, já em 1998, destacou a EAD como aprendizagem interativa, criticando a mera transmissão de conteúdos do instrucionismo, salientando transformações daí resultantes, tais como: de uma aprendizagem linear para hipermídia, em que um dado, uma informação pode sugerir outra e outra, em sentido exponencial; da instrução para a construção e descoberta, por metodologia centrada no aluno; da aprendizagem do navegar com autonomia e autoria e do aprender a aprender; do acompanhamento da necessidade individualizada do aluno; do professor como facilitador do processo.

\section{PROCEDIMENTOS METODOLÓGICOS - A Formação de Facilitadores Judiciais no AVA Plataforma NAVI/PJRS}

No programa de formação de Facilitadores Judiciais, foram delimitados objetivos de aprendizagem que convergem para a fundamentação do projeto pedagógico implementado pelo CJud/PJRS e que estão perfeitamente aderentes a respostas a desafios e possibilidades desenhados pelas características de Plataforma NAVI/PJRS.

Assim, considerando os desafios e possibilidades como aspectos positivos da educação a distância, o CJud/PJRS realiza cursos de aperfeiçoamento para magistrados, servidores e colaboradores, por meio de um ambiente virtual de aprendizagem Plataforma NAVI/PJRS, em que se prioriza o processo de aprendizagem como substrato para o desenvolvimento de competências de forma integrativa, interacional e cognitiva. 
Nesse contexto, a formação do Facilitador Judicial foi planejada para a modalidade mista, com carga horária total de 250 horas-aula, estruturando-se em nas seguintes atividades formativas presenciais e a distância. Nosso objetivo neste trabalho e apresentar o curso Curso de Formação Teórico-Prática em Justiça Restaurativa, a modalidade a distância, com carga horária de 40 horas-aula.

Durante a formação do Facilitador Judicial, foram abordados os seguintes conteúdos: noções conceituais de Justiça Restaurativa. Requisitos e princípios (Resolução CNJ no 225/2016). Enfoque restaurativo. O Facilitador e suas habilidades. Círculos de Justiça Restaurativa e de Construção de Paz. Distinção entre aplicações conflitivas e não conflitivas. Orientação dos Círculos de Justiça Restaurativa e de Construção de Paz. Utilização de ferramentas. Procedimento Restaurativo. Plano de compromisso futuro e Termos de Acordo. A Importância da participação da comunidade e das Redes de Garantia de Direitos locais.

\section{O Curso de Formação Teórico-Prático em Justiça Restaurativa}

Nosso relato se restringe à segunda etapa da formação do Facilitador Judicial, ano de 2016, ao Curso de Formação Teórico-Prático em Justiça Restaurativa, que envolveu 08 unidades judiciárias de Comarcas do Interior do Estado com 25 alunos em cada turma. As Comarcas foram: Santana do Livramento, São Borja, São Leopoldo, Taquara, Gravataí, Santa Cruz do Sul, Novo Hamburgo e Pelotas, na expectativa de certificação de 200 Facilitadores.

Ainda definindo o perfil dos alunos, tem-se que, dos 198 participantes, 21 são integrantes do Poder Judiciário do RS (10,6\%), e os demais são originários de diferentes esferas de governo e da sociedade civil, do Poder Judiciário Federal, Ministério Público Estadual, Defensoria Pública Estadual, Poder Executivo Estadual em diferentes Secretarias, Poder Executivo de diferentes municípios, unversidades, organizações da sociedade civil. Em relação à formação dos alunos originários dessas instituições, identificam-se: conselheiros tutelares, técnicos em recreação, pedagogos, psicólogos, assistentes sociais, guardas municipais, professores, dentre outros.

\section{Objetivos Específicos:}

Para esta etapa da formação - Curso de Formação Teórico-Prático em Justiça Restaurativa -, estabeleceram-se objetivos específicos, em que se esperava - ao final do curso - que os alunos fossem capazes de: a) reconhecer a importância do uso de meios alternativos de resolução dos conflitos com vistas à pacificação social e 
comunitária; b) identificar os princípios e fundamentos da Justiça Restaurativa e reconhecer as principais diferenças entre a resolução dos conflitos pelo sistema tradicional e pelas práticas restaurativas; c) contribuir com a utilização das metodologias restaurativas no seu ambiente institucional ou comunitário; e, d) sensibilizar o respectivo ambiente institucional e comunitário para a utilização das metodologias restaurativas como alternativa para abordar os conflitos.

\section{Recursos Pedagógicos e de Interação}

A complexidade estrutural, arquitetônica e operacional do processo de formação de Facilitadores Judiciais, influenciada por fatores como a quantidade de alunos, a diversidade de interesses, a variedade de serviços e a dispersão geográfica, demandou o emprego adequado de recursos de interatividade, a fim de que cada aluno se sentisse partícipe de uma comunidade de aprendizagem, baseada na afinidade de interesses na formação individual do aluno, levando-os a aportarem experiências e contribuições, para dinamizar a criação coletiva de conhecimento. Para viabilizar a interação entre os alunos e entre eles e a equipe do curso, utilizaram-se os seguintes recursos pedagógicos e de interação:

Fórum - assíncrono, destinado ao aporte de contribuições teóricas e práticas relacionadas com os conteúdos das aulas; Aula Interativa Online - discussão em tempo real - via streaming - de interação online entre aluno e professores, semanalmente, com duração de uma hora. Conteúdos - textos e legislação acessível a qualquer tempo. Videoaula - vídeos gravados pelos professores como aporte teóricoprático sobre os conteúdos do curso. Critérios de Avaliação: avaliação formativa é um processo que acompanha o percurso do estudo, das interlocuções entre os alunos e entre eles e professor e tutores, e da produção de trabalhos propostos. Atividade: plano de ação para a aplicação de práticas.

\section{Apresentação e discussão dos resultados}

A avaliação dos alunos ocorreu durante e ao final do curso, conforme plano de curso. A avaliação da aprendizagem do aluno considera seu ritmo e deve ajudá-lo a desenvolver graus ascendentes de competências cognitivas, habilidades e atitudes, possibilitandoIhe alcançar os objetivos propostos. Mais que uma formalidade legal, a avaliação procura permitir ao aluno sentir-se seguro quanto ao domínio dos conteúdos examinados. Assim, os alunos do curso de Formação Teórico-Prático em Justiça Restaurativa apresentaram os seguintes resultados que passamos a analisar. Dos 198 alunos inscritos aceitos, 122 acompanharam o curso realizando as atividades no todo ou 
em parte, sendo que 97 alunos (93\%) receberam certificados de aproveitamento (75\% freqüência nas Aulas Interativas Online e pontuação igual ou superior a 70) - e 11 alunos (7\%) obtiveram certificado de frequência (75\% freqüência nas Aulas Interativas Online e pontuação inferior a 70).

Tendo como fundamento do projeto pedagógico implementado a premissa de que o processo de aprendizagem é o substrato para o desenvolvimento de competências de forma integrativa, interacional e cognitiva, importante a verificação do alcance dos objetivos definidos para o evento formativo. Assim, o aluno deveria - ao final reconhecer a importância do uso de meios alternativos de resolução dos conflitos com vistas à pacificação social e comunitária. Tem-se, ao analisar o Fórum do dia 26/6/2017, 13h17min, dentre as contribuições dos alunos, que E. dos S. L. atinge o objetivo assim se expressando:

A noção de Justiça vai além do funcionamento do sistema jurisdicional. Passa por uma rede de recuperação de laços rompidos pelo conflito e pelo delito e chega ao âmago da questão, o lugar da subjetividade afetada.

Em relação ao segundo objetivo, de identificar os princípios e fundamentos da Justiça Restaurativa e reconhecer as principais diferenças entre a resolução dos conflitos pelo sistema tradicional e pelas práticas restaurativas, encontramos na participação de I.A.J. em 11/06/2017 02h31min, a identificação:

O que me chamou a atenção foram as mudanças ocorridas na vítima e no ofensor, através da empatia e da responsabilização durante o tempo em que durou o círculo. 0 processo proporcionou a segurança necessária para que tranquilamente cada um pudesse colocar como estava se sentindo e com o apoio do círculo, se colocando a disposição para executarem o plano de ação com reciprocidade e compreensão.

De igual forma, o objetivo de contribuir com a utilização das metodologias restaurativas no seu ambiente institucional ou comunitário, foi verificado na contribuição de M. E. S. V., em 26/06/2017 14h28min, em que o aluno conseguiu planejar em pensamento expandindo para outro ambiente a proposta de metodologias restaurativas:

\footnotetext{
Unir a comunidade nos círculos de JR, faz com que está comunidade também se responsabilize pelos atos de seus membros, cada um tem sua parcela de deveres e direitos e cada um deve assumir seu papel diante desta comunidade afetada. E os pós-círculos são importantíssimos no monitoramento das responsabilidades e mudança prospectiva destes integrantes da comunidade.
}

Também no compartilhamento de K. M. S., em 21/05/2017 22h19min, encontramos o extravasamento para a possibilidade de transformação pessoal e suas limitações, bem como a interação com o tutor, em 05/06/17 21h39min09s: 
Vejo que somente um processo de restauração das relações poderá trazer uma transformação pessoal. Lidamos diariamente com pessoas que não tem voz, e os círculos de Paz e de conflitos, são os locais onde podemos reequilibrar as relações. Dar voz a quem não tem, a quem nunca conseguiu se colocar.

S. P., em 05/06/17 21h39min09s:

K., obrigada pela contribuição, muito importante dar a voz e acreditar que todos nós temos um desejo profundo de estarmos em bons relacionamentos uns com os outros, esses são pressupostos importantes para chegarmos a responsabilização.

A partir da provocação do professor, quanto a sensibilizar o respectivo ambiente institucional e comunitário para a utilização das metodologias restaurativas como alternativa para abordar os conflitos, encontramos várias manifestações dos alunos, das quais transcrevemos:

Ao que M. A. dos S. L. escreveu em 29/06/17 22h18min49s:

\begin{abstract}
Penso que somente com a oferta contínua de um modelo diferente do que temos será possível uma mudança cultural e social na reparação e superação das causas dos conflitos. Também penso que as ideias, valores e práticas da justiça restaurativa deveriam fazer parte dos planos curriculares, desde cedo, da educação infantil. Mas entendo que o desenvolvimento de uma proposta assim deveria surgir de uma parceria entre universidades, judiciário e escolas.
\end{abstract}

Nessa perspectiva, entendemos que, no ambiente virtual de aprendizagem, viabilizado pela Plataforma NAVI/PJRS, as funcionalidades Aula Interativa Online com transmissão via streaming e Fórum proporcionam vitalidade em espaço de construção dialógica síncrona e assíncrona, entre os alunos e eles e o professor/tutor, por meio da reflexão sobre situação dada. A simultaneidade da afirmação e da réplica - uma vez que no ambiente não é necessário esperar seja concedida a palavra para expressão e contribuição de análise pessoal - enriquece o diálogo e envolve todos os participantes em um processo de compreensão de construção vivia do conhecimento. Importante salientar que a participação ativa no diálogo proporcionado no curso visa ao desenvolvimento da argumentação objetiva; da fundamentação, defesa, modificação ou rejeição de posição própria; do questionamento crítico do saber de outro aluno; da coleta de impulsos para reflexão própria e impulsão da discussão; da reflexão consciente e autocrítica com outros alunos sobre a aprendizagem havida e métodos empregados; da experimentação do progresso cognitivo coletivo; e, do procedimento racional, metódico e sistemático da exposição das próprias ideias. Assim, a metodologia EAD para desenvolvimento de competências, em que o pensar crítico autônomo é complementado com a capacidade de aplicar e experimentar a autonomia, compartilhando saberes e experiências, tem fundamento no processo de compreensão colaborativo e cooperativo. 
A capacidade de o aluno fazer a leitura de cenários, analisá-los e aplicar os conhecimentos construídos é permanentemente acompanhada e avaliada pelo professor e tutor, viabilizando uma orientação/intervenção oportuna e efetiva para a aprendizagem.

Ressaltem-se os princípios da didática da educação de adultos, sendo consideradas as condições específicas do contexto social dos alunos, suas atividades profissionais e as condições prévias inerentes à educação a distância. Há, também, que se fortalecer a socialização, de motivação, orientação no estudo, estímulo para a comunicação formal e informal entre alunos e docentes. A atratividade dos conteúdos preparados pela equipe docente, a viabilização de estabelecimento de uma comunidade com espírito e código cultural próprio, de comunicação em rede, com fluxos rápidos e leves, para socialização do conhecimento, qualificam o processo de ser e fazer por parte de cada um, proporcionando a autonomia em ser sujeito de seu processo de aprendizagem, em permanente interação dialógica com o outro. Como resultado principal desta formação no âmbito Poder Judiciário do RS, envolvendo a educação a distância como metodologia de ensino-aprendizagem, está, sem dúvida, a constatação de que a formação de Facilitadores Judiciais pode ser efetivamente realizada, com a qualidade necessária, como demonstrado pelos $93 \%$ dos alunos que receberam certificados de aproveitamento, índice amplamente satisfatório.

\section{REFERÊNCIAS BIBLIOGRÁFICAS}

BIANCAMANO, Mary. Compreensão, autoria e ética: movimentos e possibilidades em curso de gestão pública a distância. 2007. 230f. Tese (Doutorado) - UFRGS, Programa de Pós-Graduação em Informática na Educação. Porto Alegre, 2007.

TAPSCOTT, Dan. A Hora da Geração Digital. Rio de Janeiro : Agir Negócios, 2010.

ZEHR, Howard. Justiça Restaurativa: teoria e prática. Tradução: Tônia Van Acker. São Paulo: Palas Athena, 2012. 